\title{
Superficial Epithelioma with Sebaceous Differentiation
}

National Cancer Institute

\section{Source}

National Cancer Institute. Superficial Epithelioma with Sebaceous Differentiation. NCI

Thesaurus. Code C43334.

A benign epithelial neoplasm occurring in the head, neck or back region. It is characterized by proliferation of basaloid cells in the upper dermis with broad attachments to the epidermis. 